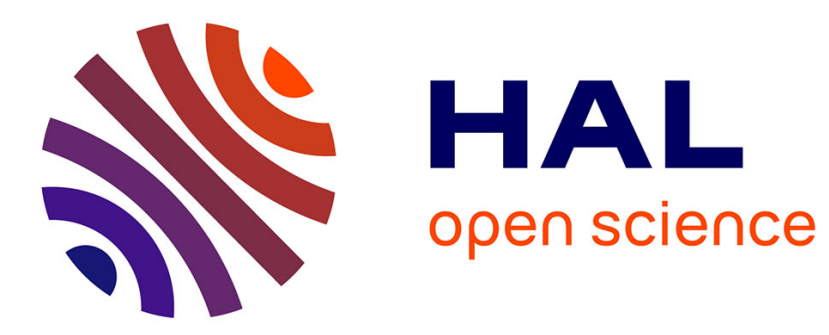

\title{
Gastrointestinal Transit of a Magnetically Marked Capsule Monitored Using a 37-Channel SQUID-Magnetometer
}

\author{
W. Weitschies, R. Kötitz, L. Trahms, D. Cordini
}

\section{- To cite this version:}

W. Weitschies, R. Kötitz, L. Trahms, D. Cordini. Gastrointestinal Transit of a Magnetically Marked Capsule Monitored Using a 37-Channel SQUID-Magnetometer. Journal de Physique IV Proceedings, 1997, 07 (C1), pp.C1-667-C1-668. 10.1051/jp4:19971272 • jpa-00254984

\section{HAL Id: jpa-00254984 https://hal.science/jpa-00254984}

Submitted on 1 Jan 1997

HAL is a multi-disciplinary open access archive for the deposit and dissemination of scientific research documents, whether they are published or not. The documents may come from teaching and research institutions in France or abroad, or from public or private research centers.
L'archive ouverte pluridisciplinaire HAL, est destinée au dépôt et à la diffusion de documents scientifiques de niveau recherche, publiés ou non, émanant des établissements d'enseignement et de recherche français ou étrangers, des laboratoires publics ou privés. 


\title{
Gastrointestinal Transit of a Magnetically Marked Capsule Monitored Using a 37-Channel SQUID-Magnetometer
}

\author{
W. Weitschies, R. Kötitz, L. Trahms* and D. Cordini* \\ Institut für Diagnostikforchung GmbH an der Freien Universität Berlin, Spandauer Damm 130, 14050 \\ Berlin, Germany \\ *Physikalisch-Technische Bundesanstalt, Abbéstraße 2-12, 10587 Berlin, Germany
}

\begin{abstract}
The gastrointestinal transit of magnetically marked solid pharmaceutical drug dosage forms can be monitored using biomagnetic measurement equipment. The presented study shows that using a 37-channel SQUID-magnetometer the investigation of the gastrointestinal transit of an ingested magnetically marked capsule becomes feasible with a temporal resolution in the order of milliseconds and a spatial resolution in the millimeter range.
\end{abstract}

\section{INTRODUCTION}

A prerequisite for the development of oral drug dosage forms is the knowledge about their gastrointestinal transit [1]. In particular, the transit times through the different parts of the gastrointestinal tract [2] and the location of dissolution or drug release [3] are of major importance. Usually, drug dosage forms labelled with $\gamma$-emitting radioisotopes are detected by scintillation cameras ( $\gamma$-scintigraphy) [4]. $\gamma$-Scintigraphy provides sufficient information, but its applicability is limited by the use of radioactive isotopes. Therefore, there is need for alternative methods for the investigation of the gastrointestinal transit of drug dosage forms.

In this study an ingested solid oral drug dosage form is magnetically marked by ferrimagnetic iron oxide and is localized by means of biomagnetic measuring procedures. This includes the use of Superconducting Quantum Interference Devices (SQUIDs) as magnetic field detectors. In former studies we showed that the detection of magnetically marked oral drug dosage forms is possible [5, 6]. We could furthermore show that the high motility of the gastric organs produces rapid marker dislocations that complicate its localization if the measuring device is a 7-channel SQUID. Sequential measurements that simulate a 21-channel detector are sufficient for the localization of the marker at locations with low motility. At about 24 hours after ingestion the localization of an ingested steel ball has already been shown to be possible even using a 1-channel SQUID [7]. This is probably due to phases of strongly reduced motility in the colon. Here we show that a 37-channel SQUIDmagnetometer is sufficient for the localization of an ingested magnetically marked capsule even throughout motility phases of the gut.

\section{MATERIALS AND METHODS}

$0.5 \mathrm{~g}$ poly(methyl methacrylic acid) were dissolved in $7.6 \mathrm{~g}$ acetone and $1.9 \mathrm{~g}$ isopropylalcohole. $2.7 \mathrm{~g}$ of powdered magnetite were dispersed in this solution by agitation with ultrasound for 5 minutes. The dispersion was sprayed onto $50 \mathrm{~g}$ of sucrose pellets (diameter $0.8-1.0 \mathrm{~mm}$ ) in a pelletiser. By this procedure about $50 \mathrm{\mu g}$ magnetite were added to each pellet. Thereafter a solution prepared of $0.5 \mathrm{~g}$ poly(methyl methacrylic acid), $0.1 \mathrm{~g}$ dibutylphtalate, $0.9 \mathrm{~g}$ isopropylalcohole and $3.6 \mathrm{~g}$ acetone was additionally sprayed onto the pellets. The pellets were proven to be insoluble in water, $0.1 \mathrm{M}$ hydrochloric acid, and phosphate buffer pH 6.9 for at least $48 \mathrm{~h}$. In order to simulate a solid unit oral drug dosage form this pellet was enclosed in a cylindrical capsule (length $16.1 \mathrm{~mm}$, diameter $5.7 \mathrm{~mm}$ ) of silicone rubber. Finally the capsule was magnetized in a short solenoid.

The measurements were performed in the Berlin Magnetically Shielded Room (BMSR) [8]. The z-component of the magnetic field $\left(B_{z}\right)$ of the marker was recorded by a 37-channel SQUID-magnetometer [9], connected to a data acquisition system with a sampling frequency of $250 \mathrm{~Hz}$.

A male volunteer who was in the fasted state for at least twelve hours was positioned under the SQUID-magnetometer in such a way that the $x$-y-plane of the SQUID-sensors was parallel to the volunteers chest. After starting the signal acquisition the volunteer ingested the magnetically marked capsule together with $50 \mathrm{ml}$ water. After 30 minutes recording time the volunteer was allowed to leave the BMSR. 30 minutes later the next signal acquisiton of 10 minutes duration was started. Such signal 
acquisitions of 10 minutes duration were repeated several times. The latest time point of signal acquisition was performed six hours after ingestion.

\section{RESULTS}

The magnetic dipole moment of the marker was determined as $6.24 \mu \mathrm{Am}^{2}$. From the $\mathrm{B}_{\mathrm{z}}$-values measured simultaneously at 37 positions and the given dipole moment of the marker its $x, y, z$ position coordinates and its orientation were calculated as previously described [10] for each sampled time point. The data obtained with the 37-channel SQUnD-magnetometer were sufficient for successful determinations of the marker positions. As an example figure 1 shows the marker positions in the $x-$, $y$-, and z-direction starting $10 \mathrm{~s}$ after ingestion for the following 2 minutes. They represent the passage of the marker from the esophagus into the stomach. Figure 2 shows a $3 \mathrm{D}$-view of the marker positions.

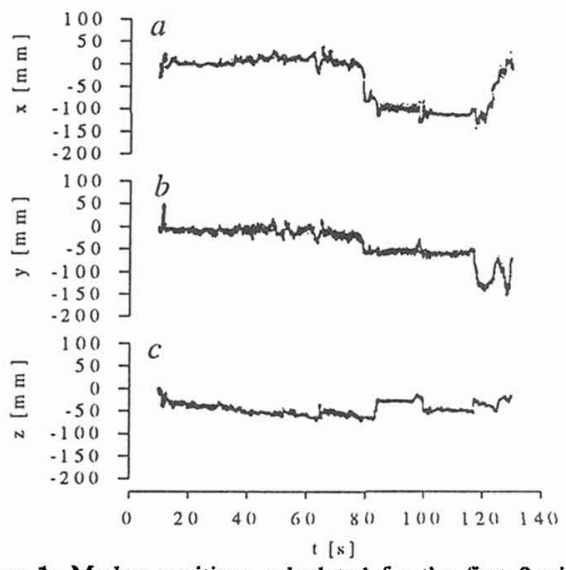

Figure 1: Marker positions calculated for the first 2 minutes after ingestion. $a$, Movement in x-direction. $b$, Movement in $y$ direction. $c$, Movement in z-direction. The origin of the coordinate system is set to the first lincalization of the marker $10 \mathrm{~s}$ after ingestion.

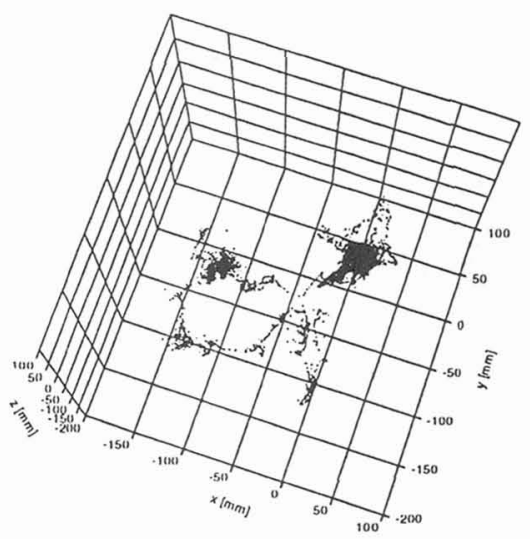

Figure 2: 3D-view of marker positions calculated for the first 2 minutes after ingestion. The chest of the volunteer is crientated in the $x-y$-plane.

\section{CONCLUSIONS}

The use of a 37-channel SQUID-magnetometer allows the localization of solid oral dosage forms that are labelled with remanent ferromagnetic or ferrimagnetic substances within the gut. A sampling frequency of $250 \mathrm{~Hz}$ provides a temporal resolution of the motion in the millisecond range. The presented method avoids the currently necessary use of $x$-rays or radionuclides. Further studies using markers that are soluble in the gastrointestimal tract might enable the in vivo determination of the time course and localization of the disintegration of solid oral dosage forms.

\section{References}

[1] Fell J.T.and Digenis G.A., Int. .J. Pharm. 22 (1984) 1-15

[2] Theeuwes F., Novel drug delivery systems. In: Drug Adsorption, L.F. Prescott and W.S. Nimmo Eds. (MTP Press, Lancaster, 1981) pp. 156-176

[3] Staib A.H., Loew D, Harder S., Graul E.H. and Pfab R, Eur. J. Clin. Pharmacol. 30 (1986) 691-697

[4] Davis S.S., The use of scintigraphic methods for the evaluation of drug dosage forms in the gastrointestinal tract. In: Topics in Pharmaceutical Sciences, D.D. Breimer and P. Speiser Eds. (Elsevier, Amsterdam, 1983) pp. 205-215

[5] Weitschies W., Wedemeyer J., Stehr R. and Trahms L., Pharm. Pharmacol. Lett. 1 (1991) 45-48

[6] Weitschies W., Wedemeyer J., Stehr R. and Trahms L., IEEE Tran.s. Biomed. Eng. 42 (1994) 192-195

[7] Di Luzio S., Comani S., Romani G.L., Basile M., Del Gratta C. and Pizzella V., Il nuovo cimento D 11 (1989) 18531859

[8] Erné S.N., Hahlbohm H.D., Scheer J. and Trontelj Z., The Berlin magnetically shielded room (BMSR): Performances. In: Biomagnetism, S.N. Erné, H.D. Hahlbohm and H. Lübbig Eds. (de Gruyter, Berlin, 1981) pp. 78-87

[9] Koch H., Cantor R., Drung D., Erné S.N., Matthies K.P., Peters M., Ryhänen T., Scheer H.J. and Hahlbohm H.D., IEEE Trans. Magn. 27 (1991) 2793-2796

[10] Model R., Trahms L., Numerical Algorithms 5 (1993) 603-610 